\title{
The Impact of Negative News on Athletes' Performance on the Field
}

\author{
Bingkuan Zhang
}

Changde Foreign Language School
Zbk799043338@163.com

\begin{abstract}
The negative reports of various media have increasingly become an important factor affecting athletes' competition attention and performance. This study proposes to study the impact of negative news on the athletes' performance on the field. Negative news can affect athletes' attention. This paper aims to explore how to eliminate the interference of negative media reports and how to deal with it.
\end{abstract}

Keywords: mass media, news media, performance, sport, athlete

\section{INTRODUCTION}

The outcome of sports competition is determined by many factors. The key to the competition lies in the competitive strength and mental state of athletes. Generally speaking, athletes with higher competitive level have more possibility to win. A lot of books, scholarly publications, and papers have been advanced regarding the mental state of an athlete and their performance. Athletes' mental state often plays a decisive role in the success or failure of the competition, and there are many factors affecting athletes' mental state. These sources have a common standpoint, holding that the efficiency of an athlete's performance tends to reduce in the face of distraction, arguing that distractions inhibit the ability of an athlete to focus. Distractions were found to stimulate negative mood, detrimental arousal, as well as a spike in stress and anxiety levels, all of which consume mental energy. Also known as adverse media, negative news is among the major causes of distraction in athlete's performance. Negative news can be explored as any sort of unfavorable or derogatory information about a subject found on multiple news sources. In the case of athletes, like other celebrities, negative news may mean a message delivering news that the athlete or their audience would dislike, which would certainly consume a significant proportion of their mental energy and reduce their ability to focus, hence low performance.

The onset of the digital era has resulted in extraordinary access to multiple information pieces on individuals, brands, and public figures like athletes and other celebrities. From online blogs, to newspaper posts, and social sites, all of these information sources remain open to the public, upon which they base their opinions concerning the person or issue in question. These not only bring the convenience of competition and watching the competition, but also bring a new test to the psychological quality of athletes. The on-site reports, off-site reports and post competition reports of various media have gradually become an important factor that can not be ignored. In particular, negative news can cause athletes' depression, which intensifies the decline of athletes' energy and the deterioration of anger, confusion, fatigue and tension, and finally leads to the abnormal play of the game. Top athletes nowadays are held to a level beyond their sport of choice within popular culture, including some local, national, and global recognition. Michael Vick, the legendary Atlanta Falcons' quarterback, became an example of the above. He was found guilty of being a party to an unlawful dogfighting operation. An average person in society would be apprehended discreetly and spend a jail time in complete privacy, but owing to Vick's national visibility, the offense rapidly overshadowed any football accomplishments he had achieved. Vick needed a great deal of time plus brand restoration initiatives to regain credibility in professional sports. Such occurrences may be found all through the diverse sectors of pro sports. In some cases, the negative news could be as a result of an overload of data, incomplete or unconfirmed info, as well as fake news, implying that an athlete's ability to focus would still be negatively affected by negative news, whether or not the information is true. Negative news sources include (a) traditional media and sources 
of news, (b) databases of multinational bodies, and (c) blogposts or web publications, inclusive of sites that post on rackets, corruption, as well as other unlawful acts by prominent persons.

The media mentioned in this paper refers to the entity that reports or comments on the performance of athletes in the field to the public. The media can be newspaper reporters, photographers, TV commentators, viewers or people who comment on the performance of athletes through public forums and online blogs. The media's publicity and coverage of sports events can be said to have covered all aspects.

The general public, on the other hand, appears to believe that it is right and obligation to task these people to a higher level of morality and decency. Due to the public's "need-to-know," it falls upon those managing professional athletes to regulate the idea that fans get. It is sometimes insufficient to just utter the appropriate words in public. According to Edward Bernays, generally regarded as the "Godfather of Public Relations," one should demonstrate to the audience that the statements they are expressing are true. Consequently, actions are more essential than words in gaining public acceptance [1].

\section{LITERATURE REVIEW}

When it comes to the ability to concentrate and keep a positive mental attitude, mental energy is an essential element. Effective concentration and a positive attitude are vital to conserving physical energy, which translates to sustained masterly technique and focus, proper skill execution, as well as withstanding the barriers to fatigue and pain. The time used to worry about distractions drains the athlete's mental energy, effectively impacting performance [2]. As pointed out in an earlier study by Haverstraw, distractions can stem from anywhere inclusive of the presence of family or the people an athlete would want to make a good impression upon, relationship issues, trainers, unprecedented high performance, teammates, underperformance, competitors, frustrations caused by blunders, unfair criticism, and certainly the media. Likewise, Soroka and others, argue that the coverage of current news is often negative, a tendency predominantly accounted for by journalistic bias. However, the scholars further posit that media bias cannot account for all the instances of negative news worldwide. Instead, they argue on the possibility of negative news being a component of humanity that is more inclined to attend to negative news content. Since the above study contends the average person is more physiologically inclined to negative than positive news items, we can conclude that negative news on athletes tends to be more impactful on the recipient than news of their positive deeds.

\section{APPLICATION OF BUSINESS MODELS}

Top athletes, strangely enough, are regarded more seriously than politicians owing to the effect athletes have on the decisions the publics take, particularly among the youth. Celebrity sportsmen have a high and positive effect on teenagers' constructive word-of-mouth as well as brand awareness[3]. As role models, athletes are on more public scrutiny thanks to media reports. As such, instances of negative news on an athlete can be compared to negative branding, in that the audience will feel disappointed in the celebrity they look up to, while the athlete will feel shunned by the public for nor living up to their expectations [4]. Such occurrences will effectively distract the athlete in question by reducing their ability to focus, consequently hurting performance.

It is at this point that the public relations expert has to be meticulous in their client analysis. Whenever red flags are found in the life of the sportsperson, a strategy for tackling the situation must be instituted prior to becoming widely known. In so doing, any harm to the reputation of the athlete may be handled and present or potential sponsorship arrangements are not jeopardized. Nevertheless, it is clear from the drug and sex controversies involved with several athletic figures' personal lives that they are yet to come to terms with the fact that they have a new task in life: one of being the best examples for the younger generation [5].

There are numerous ways to look at public relations. L. Roy Blumenthal described it as the "impact on the broader population... that may be referred to as mass indoctrination" [6]. According to the Handbook of Public Relations, "public relations may be described as assisting an institution as well as its broader public in freely adapting to one another" [7]. The explanation by Lesley is based on the premise that PR is about establishing a relationship between the customer and the general public. For the objectives of this study, it is critical to establish an acceptable understanding of public relations and also comprehend the significance of a professional athlete's public image.

\section{ANALYSIS}

There are numerous aspects to making certain that a brand's value within the public is not fully lost when dealing with a crisis. As a procedure, $c$ risis management is meant to minimize or mitigate the harm that a crisis may wreak on an entity plus its stakeholders [8]. Concerned citizens relations team are critical in such situations and should not be underestimated or overlooked. Practitioners of public relations are essential members of teams that manage crises [9]. In the face of a profession-threatening crisis with the potential to harm the reputation of both the sports team and respective player, PR experts are essentially the first layer of protection. Three connected hazards might arise 
as a result of a crisis, including (a) the safety of the public the athlete is modelling, (b) economic damage, and (c) damaged reputations. The last two are the central topic proposed for this study.

Whereas safety of the public may be a worry in certain circumstances whenever one is addressing a pro athlete's problem, that isn't always the case. Too often, loss of revenue and reputational damage must be weighed. The representative in charge of handling the matter must be properly trained and comprehend all the concerns involved. In essence, training as a spokesperson is a critical aspect of crises training sessions. That individual must understand that they are the public's voice, and that if the concerned party in the issue is unable to respond for some reason, the representative is directly talking on their behalf. It is common knowledge that a live broadcast on CNN isn't the platform for a boss to launch their media training [10]. It explains why training amid non-crisis situations is so important for customer management. When one is ready for any probable crisis, the harm done by whatever circumstance comes will be reduced.

Without someone informing the people what is going on, they will eventually fill in on their own with no truth or reality to back up their beliefs. The answer has to be consistent no matter if it's limiting a bad impression of anything the individual has done or condemning a gossip that has no foundation in fact [11]. Instant engagement with the broadcast media expresses the idea that is purely dependent on the veracity in the words chosen by the athlete. Without doing this, the audience will make their own remarks against the athlete, forcing him or her to reply [12]. The concept of message management stems out of the notion that it is preferable to issue a comment instead of responding to questions. A coup would have happened if, within the sentence, the individual responds to the entirety of questions before they are posed. The world will be told precisely what they should be aware of in the way that the personality or pro athlete prefers, without room to make inferences or suppositions.

\section{CONCLUSION}

The impact of mass media reports on Athletes' competition performance has become an indisputable fact. The size of these effects and the results are not the same, which will vary from person to person, from matter to matter and from time to time. Various psychological states of athletes have a vital impact on the success or failure of the competition. With the existence of negative media reports at all stages of the competition, the impact on Athletes' performance in the competition may be direct or indirect.

The society will always have heroines and heroes, whose behaviors and actions will be examined. Whether or not their acts are tied to their preferred profession or attributable to the nature of being human is inconsequential. Famous personalities, on the other hand, already are subjected to intense media attention owing to how much they are worth and the very skills they have. Such intense scrutiny makes top athletes more susceptible to controversies because of excess media attention. The media is realizing that no single individual can be polished through victimization[13], implying that making them villains might also contributes to underperformance since too much criticism can lower one's self-esteem. But it does not mean they'll stop looking for someone to blame for everything.

Pro sports are vital to the worldwide social culture and have long been regarded as a viable option to conflict. William James, an American philosopher, lobbied for about having a moral that could be compared to war many decades ago[14]. That substitution concept is why individuals affiliated sporting activities get such intense scrutiny[15]. As a result, PR experts have the role of helping their bosses (top athletes) navigate cases of negative publicity throughout their professional career[16].

This research is constrained by the best knowledge of the researcher about controversial pro athletes, inclusive of the limited time to conduct this study. More study is required to look for links between unfavorable media on elite sportspersons. Other sports should be examined to expand on the results of how media influence's ability. Debacles as well as the media surrounding them should also be scrutinized from as far as the inception of professional sporting activities to date, to ensure it results into a comprehensive study. Furthermore, interviewing actual top athletes would go a long way to aid in determining if the bad publicity had an effect on their performance.

\section{REFERENCES}

[1] Bernays, E. L. (1979). Your future in a public relations career. Rosen Publishing Group.

[2] Nesi, J., \& Prinstein, M. J. (2015). Using social media for social comparison and feedback-seeking: gender and popularity moderate associations with depressive symptoms. Journal of Abnormal Child Psychology, 43(8), 1427-1438.

[3] BUSH, A. J., MARTIN, C. A., \& BUSH, V. D. (2004). undefined. Journal of Advertising Research, 44(1), 108-118. https://doi.org/10.1017/s0021849904040206

[4] O'brien, M. (2011,). 'A social pariah': How lonely Monica Lewinsky has failed to find happiness... and is STILL the butt of lewd Clinton jokes. Mail Online. Retrieved December 2, 2021, from 
https://www.dailymail.co.uk/news/article2034697/Lonely-Monica-Lewinsky-trying-playBill-Clinton-affair.html

[5] Suter, K. (2009). The Importance of Sport in Society. Contemporary Review, 332-339.

[6] Blumenthal, M. D. (1972). Predicting attitudes toward violence. Science, 176(4041), 1296-1303. https://doi.org/10.1126/science.176.4041.1296

[7] Lesley, P. e. (1983). Public Relations Handbook. Englewood Cliffs: Prentice-Hall.

[8] Coombs, W. T. (2007a). Ongoing crisis communication: Planning, Managing, and responding (2nd ed.). Los Angeles: Sage. T

[9] Coombs, W. T. (2007b). Protecting organization reputations during a crisis:The development and application of situational crisis communication theory. Corporate Reputation Review, 10, 1-14.

[10] Boynton, L. A. (2007). Commentary 1: This PR firm should have known better. Journal of Mass Media Ethics, 22(2-3), 218-221. https://doi.org/10.1080/08900520701448830

[11] Bernays, E. L. (1961). Your future in public relations.

[12] Seymour, D.T. (1991) TQM on Campus: What the Pioneers are Finding. AAHE Bulletin, 44, 10-13

[13] Von Burg, R., \& Johnson, P. E. (2009). Yearning for a past that never was: Baseball, steroids, and the anxiety of the American dream. Critical Studies in Media Communication, 26(4), 351-371. https://doi.org/10.1080/15295030903176641

[14] Giambalvo, E. (2019). How Michael Vick's dogfighting case changed animal welfare: a second chance. The Washington Post. Retrieved December 2, 2021, from https://www.washingtonpost.com/graphics/2019/sp orts/michael-vick-dogfighting-dogs/

[15] Jaksa, K. L. (2011). Sports and collective identity: The effects of athletics on national unity. SAIS Review of International Affairs, 31(1), 39-41. https://doi.org/10.1353/sais.2011.0007

[16] Lasley, T. J., Applegate, J. H., \& Ellison, C. (1986). The expectations and problems of University supervisors of early Field experiences. Journal of Education for Teaching, 12(2), 127-140. https://doi.org/10.1080/0260747860120202 